\section{Commentary: To spare or not to spare, the question is still valid for some}

\author{
Ho Jin Kim, MD, and Joon Bum Kim, MD, PhD
}

In the current issue of the Journal, Patlolla and colleagues ${ }^{1}$ described the Mayo Clinic experience of 342 consecutive patients who underwent valve-sparing aortic root replacement (VSARR) from 1994 and 2017. Among these patients, $90 \%(\mathrm{n}=308)$ received aortic root reimplantation, whereas a limited number of patients $(\mathrm{n}=34,10 \%)$ underwent remodeling. Only $34.8 \%$ of the patients had greater-thanmild aortic regurgitation (AR) preoperatively, which implies that the patients may have been judiciously selected for VSARR in this study. Operative mortality was excellent $(1.5 \%, \mathrm{n}=5)$, given that the study cohort included 19 patients with aortic dissection. Of note, $4.7 \%$ of patients ( $\mathrm{n}=16$ ) were reported to have moderate-to-severe AR at the time of discharge; unsurprisingly, the patients with remnant AR after VSARR showed poor survival.

This study adds to the growing body of evidences that suggest VSARR as a viable and safe option in the treatment of proximal aortic root aneurysm throughout the long-term follow-up period (median, 8.8 years; quartile 1-3, 4.113.5 years). ${ }^{2,3}$ The 15-year cumulative incidence of aortic valve (AV) reoperation was $17.1 \%$. Although the study was largely descriptive on the heterogenous cohort with differing valvular pathologies and surgical techniques, the robust analyses showed that concomitant cusp repair and dilated aortic annulus was associated with an increased risk of reoperation. This directs our attention to the traditionally controversial issues for VSARR: what select patients should receive VSARR by what surgeons with what techniques?

\footnotetext{
From the Department of Thoracic and Cardiovascular Surgery, Asan Medical Center, University of Ulsan College of Medicine, Seoul, Korea

Disclosures: The authors reported no conflicts of interest.

The Journal policy requires editors and reviewers to disclose conflicts of interest and to decline handling or reviewing manuscripts for which they may have a conflict of interest. The editors and reviewers of this article have no conflicts of interest.

Received for publication Oct 4, 2020; revisions received Oct 4, 2020; accepted for publication Oct 6, 2020; available ahead of print Oct 13, 2020.

Address for reprints: Joon Bum Kim, MD, PhD, Department of Thoracic and Cardiovascular Surgery, Asan Medical Center, University of Ulsan College of Medicine, 88, Olympic-ro 43-gil, Songpa-gu, Seoul, 05505, Republic of Korea (E-mail: jbkim1975@amc.seoul.kr).

J Thorac Cardiovasc Surg 2022;164:502-3

$0022-5223 / \$ 36.00$

Copyright (c) 2020 by The American Association for Thoracic Surgery

https://doi.org/10.1016/j.jtcvs.2020.10.017
}

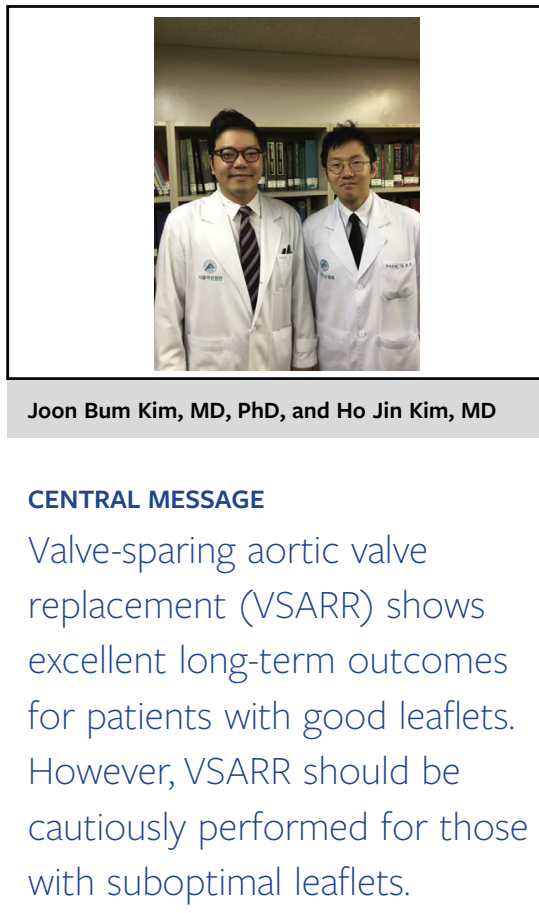

Excellent long-term outcomes after VSARR have been frequently reported in the literature, ${ }^{2-4}$ which focused on the importance of selecting patients with preferably tricuspid, good leaflets without significant AR. The results of patients with bicuspid AV were reported to be comparable with those of patients with tricuspid AV in this study; however, it was not sufficiently powered to detect the significant differences that require further verification. Similarly, concomitant cusp repair at the time of VSARR was shown to be related to the risk of reoperation. While it may be true that a highly selected group of young patients who require extensive cusp repair could benefit from VSARR by avoiding early anticoagulation, the decision to spare the suboptimal valve should be weighed against the possible association between the remnant $\mathrm{AR}$ and compromised long-term survival, as suggested in this study.

The importance of stabilizing the aortic annulus to prolong the durability of AV particularly for patients with dilated annulus was highlighted in this study, which may favor reimplantation over remodeling from technical standpoint. However, as addressed by the authors, the modified root remodeling technique with annuloplasty may provide a comparable long-term durability with reimplantation. ${ }^{5}$ The study also raised the controversial issues on the choice of graft (Valsalva vs tubular straight graft). In contrast to a univariable association between the use of Valsalva graft 
and a decreased risk of reoperation in this study, recent ex vivo study and several clinical series showed a superiority of straight graft over Valsalva graft. ${ }^{6}$ All these technical factors that may affect the long-term outcomes after VSARR requires further clarification in the future studies.

VSARR, as will be agreed by all cardiac surgeons, is a technically challenging procedure with a steep learning curve even for expert surgeons. Notably, 15 different surgeons contributed to the cohort in this study, which is a quite large number for a single-center experience. Although the authors stated that there was no difference in the operative results among surgeons regardless of the level of experience, it can be conceivable that the cases in this study included those performed by various surgeons over learning curve period. This may partly account for the discrepancies in the outcomes from other studies performed by a minimum of surgeons. ${ }^{2,3}$ However, this study may better reflect real-world outcomes that cardiac surgeons who consider VASRR as a surgical option in their practice may better reference. To spare or not to spare is not clearly the question for the patients with normal leaflet cusps, particularly when performed by expert surgeons with profound experiences. However, for those who are deemed at high risk for failure, endeavors should be continued to broaden the boundaries of VSARR by carefully selecting the patients and optimizing the outcomes with quests on appropriate techniques and graft choices.

\section{References}

1. Patlolla SH, Saran N, Dearani JA, Stulak JM, Schaff HV, Greason KL, et al. Outcomes and risk factors of late failure of valve-sparing aortic root replacement. $J$ Thorac Cardiovasc Surg. 2022;164:493-501.e1.

2. Mastrobuoni S, de Kerchove L, Navarra E, Watremez C, Vancraeynest D, Rubay J, et al. Long-term experience with valve-sparing reimplantation technique for the treatment of aortic aneurysm and aortic regurgitation. J Thorac Cardiovasc Surg. 2019;158:14-23

3. David TE, David CM, Feindel CM, Manlhiot C. Reimplantation of the aortic valve at 20 years. J Thorac Cardiovasc Surg. 2017;153:232-8.

4. David TE, David CM, Ouzounian M, Feindel CM, Lafreniere-Roula M. A progress report on reimplantation of the aortic valve. J Thorac Cardiovasc Surg. September 4, 2020 [Epub ahead of print].

5. Lenoir M, Maesen B, Stevens LM, Cartier R, Demers P, Poirier N, et al. Reimplantation versus remodelling with ring annuloplasty: comparison of mid-term outcomes after valve-sparing aortic root replacement. Eur J Cardiothorac Surg. 2018;54:48-54.

6. Paulsen MJ, Kasinpila P, Imbrie-Moore AM, Wang H, Hironaka CE, Koyano TK et al. Modeling conduit choice for valve-sparing aortic root replacement on biomechanics with a 3-dimensional-printed heart simulator. J Thorac Cardiovasc Surg. 2019; 158:392-403.

\section{Commentary: Studying the art of mastery, or judgment over technique}

\section{Dawn S. Hui, MD, and John H. Calhoon, MD}

Perhaps the trait by which surgeons are most judged is that of technical skill. This stance is reflected in quotes such as "A chance to cut is a chance to cure." In later days, these skills have expanded to the use of new approaches and devices. In his 2013 Presidential Address, Dr Hartzell Schaff gave us insight into his view, stating this his "posture [is] not

\footnotetext{
From the Department of Cardiothoracic Surgery, University of Texas Health Science Center at San Antonio, San Antonio, Tex.

Disclosures: The authors reported no conflicts of interest.

The Journal policy requires editors and reviewers to disclose conflicts of interest and to decline handling or reviewing manuscripts for which they may have a conflict of interest. The editors and reviewers of this article have no conflicts of interest.

Received for publication Oct 4, 2020; revisions received Oct 4, 2020; accepted for publication Oct 6, 2020; available ahead of print Oct 13, 2020.

Address for reprints: Dawn S. Hui, MD, Department of Cardiothoracic Surgery, University of Texas Health Science Center at San Antonio, 7703 Floyd Curl Dr, San Antonio, TX 78258 (E-mail: huid@uthscsa.edu).

J Thorac Cardiovasc Surg 2022;164:503-4

$0022-5223 / \$ 36.00$

Copyright (c) 2020 by The American Association for Thoracic Surgery

https://doi.org/10.1016/j.jtcvs.2020.10.016
}

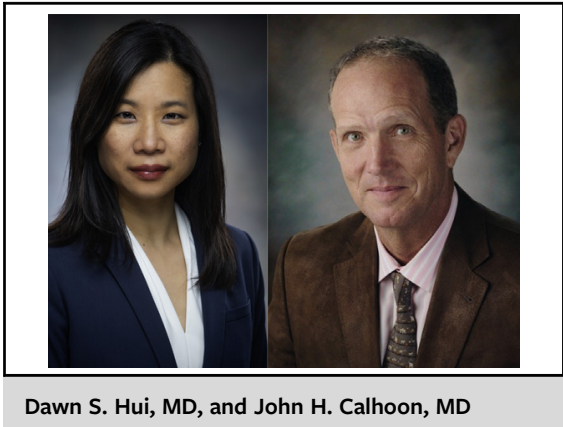

CENTRAL MESSAGE

A large series on valve-sparing aortic root replacement substantiates the importance of experience and refinement in technique over time to achieve excellent long-term outcomes.

to lead by doing necessarily every new operation or using every new device, but to use judgment when implementing new techniques."1 